\title{
The Move to Middle School: Parents' Expectations and Early Adolescents' Adjustment in Rural Communities
}

\author{
Jill V. Hamm ${ }^{1}$, Kimberly A. Dadisman ${ }^{2}$, Kathleen M. Day ${ }^{1}$, Charlotte A. Agger ${ }^{1} \&$ Thomas W. Farmer $^{3}$ \\ ${ }^{1}$ Center for Developmental Science, University of North Carolina at Chapel Hill, Chapel Hill, NC, USA \\ ${ }^{2}$ Abt Associates, Boston, MA, USA \\ ${ }^{3}$ Virginia Commonwealth University, Richmond, VA, USA \\ Correspondence: Jill V. Hamm, Center for Developmental Science, CB 8100, University of North Carolina at \\ Chapel Hill, Chapel Hill, NC 27599, USA. Tel: 1- 919-843-8390. E-mail: jill.hamm@unc.edu
}

Received: October 11, 2013

Accepted: November 15, 2013

Online Published: December 24, 2013

doi:10.5539/jedp.v4n1p46

URL: http://dx.doi.org/10.5539/jedp.v4n1p46

This work was supported by grant No. R305A04056 from the Institute of Education Sciences. The views expressed in the manuscript are those of the authors and do not represent the granting agency.

\begin{abstract}
Parents' expectations for the middle school transition were investigated in 10 focus groups with 37 parents in two rural Appalachian communities. Parents emphasized their concerns over the social aspects of the transition for their children, particularly relationship changes and exposure to problem behaviors through peers. Moreover, parents whose children attended certain feeder schools feared their children would be socially marginalized in middle school. Student adjustment data collected from $1876^{\text {th }}$ graders in the associated middle schools were analyzed for evidence of social marginalization or poor adjustment by feeder elementary school. With few exceptions, social integration did not differ by feeder school but students from a particular feeder school experienced greater adjustment difficulties overall, according to self- and teacher-ratings. The findings highlight the need for schools to help parents understand the social transition to middle school and to monitor student adjustment when there are discrepancies across feeder schools.
\end{abstract}

Keywords: middle school transition, parent expectations, social integration

\section{Introduction}

The transition into middle school represents a significant undertaking for youth. Early adolescents typically move from a small, familiar school environment to a larger, unfamiliar school setting, forge new relationships with teachers and students, and learn and negotiate novel norms, routines, and expectations (Anderman \& Mueller, 2009). The middle school transition is challenging for early adolescents regardless of geographic locale, and rural youth are no exception. Recent large-scale and longitudinal studies of rural early adolescents document small but significant declines to academic achievement (Stanley, Comello, Edwards, \& Marquart, 2008), significant deterioration of school belonging (Hamm et al., 2010; Perry \& McIntyre, 2001; Witherspoon \& Ennett, 2011), and significant increases in physical and social aggression with peers (Karriker-Jaffe, Foshee, Ennett, \& Suchindran, 2008) and school misbehaviors (Witherspoon \& Ennett, 2011).

Early adolescents' adjustment in the middle school transition is typically understood from a stage-environment fit perspective (Eccles et al., 1993), which focuses on the match between early adolescents' developmental needs and the demands of the school environment. Recent conceptualizations of school transitions expand on this view to include greater attention to the role of parents and features of the sociocultural context within which families help their children make successful school transitions (Doucet \& Tudge, 2007). Parents are recognized for their critical role in young children's transition into school in general and specifically in rural areas (i.e., Vernon-Feagans, Gallagher, \& Kainz, 2010), but are largely absent in the study of early adolescents in the middle school transition. 


\subsection{Importance of the Problem}

Parents often hold strong views concerning their adolescents' adjustment, and their beliefs are associated with their children's subsequent adjustment (Buchanan \& Hughes, 2009; Jacobs, Chhin, \& Shaver, 2005). However, studies of parents have addressed expectations of adolescence in general (i.e., as a stormy and stressful period of life), not specific milestones in adolescents' lives, such as the middle school transition. Understanding parents' expectations for the move to middle school may be particularly important, given that rural adolescents look to their parents, more so than to peers or teachers, for information and advice about schooling experiences (Griffin, Hutchins, \& Meece, 2011).

\subsection{Relevant Scholarship}

In one of the few studies of parental views of the middle school transition, parents' expectations were classified into one of three domains: academic (e.g., dealing with homework), procedural (e.g., getting lost, getting to school on time), and social (e.g., ability to manage social pressures). Moreover, parents expected significant difficulty for each domain. Yet, the families that participated in this study resided in an affluent suburban community with academically successful schools and substantial school-based transition programming in place (Akos \& Galassi, 2004). Although the domains of the middle school transition (i.e., academic, procedural, and social) may be consistent across communities, parents' expectations for their children's adjustment in these domains may reflect the nature of the community context in which the transition occurs.

Rural middle schools tend to be large, regional schools that serve broad economic and geographic areas within a large county school district. They can be locally controversial, as many have resulted from state-mandated school consolidation. States with large rural areas, such as the Appalachian states, have consolidated in part in response to the middle school movement, but largely to reduce expenses associated with large numbers of small schools (DeYoung, Howley, \& Theobald, 1995; Duncombe \& Yinger, 2007; National Rural Education Association [NREA], 2006). Although regional middle schools in rural areas may allow for greater depth and breadth in course offerings and advance rural youths' viability in the national labor force (NREA, 2006), opponents have argued that rural student achievement and extracurricular participation is greater in smaller than in larger schools and emphasize the negative impact on youth when they must travel out of their local communities (Tompkins, 2006; Spence, 2000; Lewis, 2006). Ethnographic studies of rural areas have detailed community members' (e.g., parents') views of school consolidation, lamenting the loss of the local school's socialization of the community's values. In addition, parents lost their ability to stay involved with their children's schooling, as consolidated schools are often no longer in close proximity to the family (DeYoung et al., 1995; Peshkin, 1982; SanAntonio, 2004). Such issues may contribute to parents' expectations about the transition. For instance, parents may expect procedural difficulties for their children related to parents' lack of familiarity with the school campus and their reduced ability to maintain a presence at the school.

Rural areas (e.g., Appalachia) are also strongly socially stratified, with poorer and geographically isolated areas marginalized in ways that adversely affect social interaction between local communities (Duncan, 2001; Thorne, Tickamyer, \& Thorne, 2007). School consolidation practices typically position middle school as the first schooling level at which youth from diverse social strata meet. In ethnographic studies of both school consolidation and the middle school transition, parents of adolescents expressed concerns over who their children would be exposed to in the middle school context related to this stratification. Moreover, students of different social strata served by regional middle schools were keenly aware of the perceptions of their local communities by the larger community and hold derogatory views of individuals outside their local communities (DeYoung et al., 1995; Nitta, Holley, \& Wrobel, 2010; Peskhkin, 1982, SanAntonio, 2004). Such dynamics may play a role in the expectations about the social transition of middle school and may also contribute to different interpretations of the transition issues by parents from different local areas served by the same middle school.

Beyond the conditions that consolidated rural middle schools create, the cultural context of family life in Appalachian communities may contribute to parents' expectations for the middle school transition. In general, positive family-school relationships are challenging in rural communities, with parents reluctant to engage with school personnel around their children's education and adjustment (Semke \& Sheridan, 2012). Rural parents' educational aspirations and expectations for their children tend to be lower than those of urban and suburban parents (Beaulieu, Israel, \& Wimberley, 2003); low aspirations among rural Appalachian parents may affect the extent to which they are concerned about their youths' academic adjustment (Wallace \& Diekroger, 2000, as cited in Ali \& Saunders, 2008; Wilson, Peterson, \& Wilson, 1993). Rural Appalachian parents may view the academic domain of the middle school transition with some ambivalence, as educational attainment may result in 
youths' departure from the local community (DeYoung, 2007). An understanding of parents' expectations for the middle school transition provides insight into how youth are prepared to make the move to middle school.

\subsection{Research Questions and Design}

The challenges inherent in the middle school transition in rural communities and the adjustment difficulties that rural early adolescents face in this transition call for examination of parents' expectations about the middle school transition in these communities. Data for the present study are from two rural, Appalachian communities that were pilot sites for a larger intervention research project, Project REAL (Rural Early Adolescent Learning). In these pilot sites, a professional development program for sixth-grade teachers was developed, and survey data were collected from students and teachers regarding students' social, behavioral, and academic adjustment as students made the middle school transition. As a supplement to these components of the larger research project, we conducted focus groups with $5^{\text {th }}$ (pre-transition) and $6^{\text {th }}$ (post-transition) parents, to explore the nature of parent expectations of the middle school transition. We center the present study on parents, but in a follow-up study, use the survey data collected from the majority of students in each school to examine the extent to which some of the concerns espoused by focus group parents about the middle school transition manifested themselves in the actual adjustment of students in these schools during the middle school transition year. The findings from both the focus groups and the follow-up analyses of survey data for the larger student body contribute to an understanding of rural parents' perspectives on the transition and provide a systematic study of the social integration and adjustment of students as they move from local elementary schools to consolidated middle schools in rural communities.

\section{Method}

The focus group study involved parents of $5^{\text {th }}$ and $6^{\text {th }}$ graders in two Appalachian communities, Mountainside and Valleyview, in two different states. The schools had been selected for participation as pilot sites in Project REAL, based on the demographic characteristics of the communities and schools. Project REAL was a large-scale research intervention study that was part of the National Center for Research on Rural Education Support (www.nrcres.org); REAL ultimately involved 36 rural schools across the United States. However, the focus of the larger Project was on teachers and students; parent focus groups were conducted only in the Appalachian pilot sites as a study supplement.

\subsection{Community and School Contexts}

Table 1 summarizes background information on the two towns. At the time of the study, both were designated as a locale 6 (a region not within a larger metropolitan statistical area and not within a metropolitan statistical area with a population of at least 2,500 and no more than 25,000) by the National Center for Education Statistics (NCES). Both towns are in an 80-mile proximity of a city of 50,000 or greater; both communities have access to an interstate within 20 miles. Historically, the primary economic base for both communities has been coal mining and agriculture; more recently, according to state documentation, service and light manufacturing industries have expanded.

Table 1. Community statistics

\begin{tabular}{lll}
\hline Community Characteristics & Valleyview & Mountainside \\
\hline Approximate Size of Community & 6,000 & 4,000 \\
Percentage in Community with College/High School Degree & $12.1 \% / 55 \%$ & $17.3 \% / 58 \%$ \\
Unemployment Rate & $21 \%$ & $6.7 \%$ \\
Median Household Income & $\$ 26,941$ & $\$ 27,554$ \\
\hline
\end{tabular}

Note: Source: http://nces.ed.gov/

\subsubsection{Mountainside Schools}

Parents had children in one of three schools in this district: Mountainside Middle, Mountainside Elementary, and New Mountainside Elementary. According to school district personnel, Mountainside Middle became a 6-8 grade middle school in 1980; the elementary schools have served grades K-5 since that time, as well. Review of county school board documents for the year of the study and local newspaper articles revealed that consolidation 
at elementary and high school levels was under formal consideration, due to poor school facilities and declining student enrollment. Schools in this district were over $94 \%$ White and $50 \%$ or more of the students in each school received subsidized meals through the National School Lunch Act. According to state designations of family economic disadvantage, Mountainside elementary, compared to New Mountainside elementary and Mountainside Middle, served a greater proportion of children from low-income families ( $62 \%$ versus $52 \%$ and $52 \%$ of student bodies, respectively). In the academic year preceding the study, Mountainside elementary enrolled approximately 350 students; New Mountainside enrolled approximately 600 students, and Mountainside Middle enrolled approximately 550 students. All schools had attained Annual Yearly Progress (AYP).

\subsubsection{Valleyview Schools}

Families were associated with one of three schools in this district: Valleyview Middle, County Elementary, and Perkins Elementary. According to school district personnel, Valleyview Middle became a 6-8 grade school in 1998; prior to this point it served as the town's junior high and prior to that it had served as the town's high school. Consolidation had taken place recently at the elementary school level. In 2001, County and Perkins transitioned from grades K-5 to grades 3-5 schools and three district elementary schools (K-5) were closed. In many study families, older siblings had attended one of the defunct elementary schools. The elementary schools had attained AYP in the prior to the study year, but Valleyview Middle had not. Roughly $50-75 \%$ of the student body of each school was eligible for free or reduced lunch under the National School Lunch Act. Of the two elementary schools, the student body of Perkins had a higher percentage of students classified as economically disadvantaged ( $73.7 \%$ versus $47.3 \%$ of students classified as economically disadvantaged by state indicators). For the school year of the study, County enrolled approximately 330 students, Perkins approximately 200, and Valleyview Middle approximately 600 students.

\subsection{Parent Participants}

A total of 37 parents of a $5^{\text {th }}$ or $6^{\text {th }}$ grade youth in one of the elementary or middle schools in Mountainside or Valleyview participated in one of 10 focus groups during October and November. A summary of parent characteristics is reported in Table 2.

Table 2. Summary characteristics of the focus groups

$\begin{array}{ll}\text { Group (No. of } & \text { School Description } \\ \text { Participants) }\end{array}$

Mountainside Middle

Mothers of multiple children who had gone through middle school transition. Three White, one African American mother. One mother described difficult life circumstances, including chronic illness and family poverty. One mother had moved to the area within the past few years; others were long-term residents. All parents were employed in blue-collar positions. Parents did not know one another.

Mountainside Middle

One mother, two fathers of youth; all had previous children transition into middle school. All parents were employed in blue-collar positions. All parents were White. Parents did not know one another.

Mothers of daughters; one had an older daughter who made the middle

Valleyview Middle school transition several years earlier. Both were teachers (early childhood and business). Parents knew one another through their children. Both parents were White.

Mothers of son and daughters making the transition. Two parents were Valleyview Middle teachers in area schools; one was a PTO officer at the school and unemployed. All parents were White. Parents had some familiarity.

Four mothers and a father of sons and daughters; some parents were new to the middle school transition. Father was the PTO president. One Perkins Elementary parent was a local minister, one was a special education aide in the school; the remaining parents did not work. Parents had some familiarity. 
Five mothers of sons and daughters; one mother was African American and a foster parent of child going through middle school transition. Perkins Elementary Parents identified their marital status; two were married and three were divorced or separated. Parents reported recognizing one another from school only.

All White mothers and one grandmother (custodial parent) of sons and daughters. All described their children as struggling academically. One

County Elementary parent had met with the principal that day about a complaint about the school; the principal encouraged her to attend the focus group to (in his words) ensure a diversity of perspectives. Parents reported not knowing one another.

Two mothers and a grandmother (custodial parent), all White. One County Elementary mother and grandmother had college degrees and were self-employed and retired (respectively); the other had a high school degree and did not work. Parents recognized one another from the school setting.

Four White mothers of sons and daughters; 2 with prior middle school transition experience with older children. One was a PTO officer and not

Mountainside Elementary employed, one was a discount store manager, one was a farmer, and one was a school bus driver. None had attended college. Three were divorced (one remarried); one was married. Group members self-identified as "older" - three were over 40 years of age; one was in her late 30s.

One African American mother, one White mother, one White father. New MountainsideThis was the shortest group; parents were not as talkative as in other Elementary groups. Parents did not know one another. Parents were employed in blue-collar positions.

\subsection{Procedures}

Conceptualizations of expectations derived from research on affluent parents in suburban communities offer potential for understanding the perspectives of rural Appalachian parents, but their appropriateness is unclear, as research suggests that values, belief systems, and behaviors of families in rural Appalachia may differ from those in suburban settings. Thus, focus group methodology was chosen, based on the desire to generate discussion of parental views of the transition. When groups are assembled based on participant similarity that is relevant to the study, such as having a child preparing for, or currently experiencing the middle school transition, self-disclosure of perspectives and experiences is promoted. At the same time, the group format allows for disagreement in views that results in additional discussion of points for clarification and elaboration of views (Hughes \& Dumont, 1993; Krueger, 1994). Researchers have demonstrated the appropriateness of focus group methodology for research on parents in rural communities (Farmer et al., 2006; Owens, Richerson, Murphy, Jageleweski, \& Rossi, 2007).

We worked directly with school personnel to identify and recruit participants. As part of our larger research project, we had a working relationship with staff members at each school who understood the purposes of Project REAL as a whole and who acted as liaisons between our project and other school personnel. These liaisons initially identified approximately 10-15 representative families (by race/ ethnicity, gender of child, student achievement, parent orientation toward school) from the target grade in their school ( $5^{\text {th }}$ for elementary, $6^{\text {th }}$ for middle). Schools mailed recruitment fliers to these families at two time points. Liaisons strongly advised against combining parents across different schools, citing concerns that this would create discomfort among parents that would undermine the dynamics and discussion we sought. They also recommended that groups meet in the schools that children attended. These suggestions were aligned with guidelines for creating homogeneity within focus groups (Krueger, 1994).

On the scheduled date and time for each school, roughly 5-10 parents arrived to participate; researchers created one or two focus groups per school, distributing parents between groups in terms of the target child's gender and whether or not parents had older children who had made the middle school transition (See Table 2). Meals and 
snacks were provided to parents prior to the focus groups, as was a $\$ 50$ appreciation payment at the close of the interview. The first two authors conducted and audio-recorded all focus group discussions.

Following informed consenting procedures, the moderator led introductions and described the study aims. Then, the moderator initiated discussion with a general question about parents' thoughts either in anticipation of or about their child's middle school transition. Parents carried the discussion with little intervention from the moderator except when the group got off topic or the moderator wished to support individual members' participation (e.g., inviting parents who had not commented to weigh in, or noticing that someone had wished to make a point but had been unable to do so before the discussion changed). In general, parents quickly developed an active dialogue; the moderator's role was to insert questions that followed up on participants' prior comments. Although an initial set of questions was devised to guide the discussion if necessary, this protocol was not followed verbatim. Toward the end of the focus group meeting, the moderator returned to questions on the protocol that addressed topics that were not spontaneously raised by the group.

\subsection{Data Coding}

Audio recordings of the interviews were transcribed professionally and the resultant text files were corrected by the authors for accuracy. Atlas-TI software was used to apply codes to the transcribed text files. Following recommendations for the analysis of focus group data, we coded parent dialogues; that is, exchanges about an idea across multiple participants, rather than the comments of any single parent within the group (Krueger, 1994). However, we note that when we included parent quotations to illustrate a point in the Results, we often shortened the text to the comment of a single parent in order to save space.

Prior to conducting the interviews, we had identified specific initial codes based in the literature; namely, characterizations of the middle school transition as academic, social, and procedural in nature. As transcripts became available, the first author conducted a first layer of coding of each interview, focusing exclusively on the social, academic, and procedural codes. Once this first layer of coding was completed, we submitted code queries within the Atlas-TI program to generate reports of the dialogues associated with the social, academic, and procedural codes. We applied a second layer of coding to the dialogues associated with each code using fine-grained categories that we identified in the following two ways. First, following completion of each focus group interview, the first two authors had a debriefing meeting for 1-2 hours during which we discussed the content of each interview and identified and noted additional categories that reflected the greater specificity of parents' discussions regarding the academic, social, and procedural aspects of the transition, as well as additional topics that arose in multiple groups. We summarized these discussions and suggested categories in written memos. Second, once the first layer of coding was completed, the first two authors discussed dialogues associated with each code, reviewed the memos from the debriefing meetings, and refined the categories to be applied to the social, academic, and procedural dialogues. Fine-grained categories were included if they emerged in two or more interviews. Examples of the fine-grained categories that were added based on these processes and that are relevant to the present study included "relationship transitions," "exposure to deviant peers," and "school preparation."

As transcripts were coded, the first and second authors reviewed one another's coding. Disagreements were rare and were discussed and revised, if necessary, following resolution of the discussion. At the conclusion of the second layer of coding, we again submitted code queries to obtain summaries of the data associated with the fine-grained categories within each code. The first two authors reviewed these reports and identified shared parent perspectives that were represented across groups, as well as views that diverged from the shared perspectives. Additional reports were generated that sorted the data associated with codes and fine-grained categories within codes by the gender and age of the child in transition $\left(5^{\text {th }}\right.$ versus $6^{\text {th }}$ grade). The authors reviewed the dialogues that were sorted by gender and could not discern differences in parents' discussions based on the gender of their child. Our analyses of distinctions of dialogues between parents of $5^{\text {th }}$ versus $6^{\text {th }}$ graders are included in the Results section.

Finally, all quotations representing codes reported in the Results were checked against the original transcript for the focus groups to ensure that excerpts were not misinterpreted out of the context of the larger interview. The findings reported here reflect recurring and shared perspectives among parents within and across groups. Overall, there was considerable agreement among parents in terms of the content discussed; differences in opinion are presented when they occurred, as are parent perspectives that were localized to some, but not all, groups. Where possible, we followed up on specific comments about schools and communities by consulting public documents, 
including school board records and local newspaper articles, to obtain verification of and greater information about relevant points.

\section{Results}

The results of our analyses indicated that the focus of parents' discussions - both in content and emphasis concentrated on the social domain of the transition. As is evident in these excerpted quotations below, which were chosen because they represented the discussions that occurred in each focus group, parents readily discussed the challenges of the middle school transition, but maintained strong concerns about the social transition in particular:

P3: The social issue probably has been more important than the academic issue, as you [another parent] have pointed out ... [FG5]

P1: The getting about in the school to me is secondary... I worry more about the older kids being with them, and it's such a fragile age, 11, 12, 13. [FG 10]

P3: There at first it was the academic, because everything was so different and hard...it seemed like the more in, it got more social. The kids, just for lack of a better term, were mean ... She said, "Everyone is against me." And not that she's not a likable child, she is. It's just the pressures out there at that middle school. It's like [parent] said, the drugs are bad out there. The pushing for them to have sex out there is bad. I mean, you would really be amazed at some of the things that's going on out there. It was hard when we were in middle school, but it's even harder now for them. [FG 9]

As elaborated below, we concentrate on parents' discussion of the middle school social transition, given the prominence of this topic in the focus groups and parents' own emphasis of the salience of this dimension. Following our analysis of the social domain, we provide a brief summary of parents' discussions of the procedural and academic domains of the transition.

\subsection{Social Domain of the Transition}

Across focus groups, parents' discussions focused consistently on two related social issues: falling prey to bad influences of older students and changing friendships across the transition. These topics were raised and actively discussed by parents in each focus group.

\subsubsection{Falling Prey to Bad Influences}

Members of all focus groups discussed the problematic exposures introduced in $6^{\text {th }}$ grade through contact with a more heterogeneous and older group of students - most prominently in terms of illegal substances; less frequently for bad language and sexual promiscuity. The first excerpt comes from the middle school focus group for Mountainside, with comparable views expressed in each of the $5^{\text {th }}$ grade parent focus groups. No parents disagreed with this theme in any focus group.

P3: That's something you've got to try to instill into them, not to do what everybody else does, because there's, I don't know whether you know about it or not, but there's a drug problem in [County].

P1: Oh yeah.

P3: I worry about that too. I've preached to both my young'uns. They're coming to us and talking to us about it, but I know there are people here in the schools that approach them, and I worry about them getting into drugs myself, but hopefully we'll be all right [FG2].

Similarly, in Valleyview, the following commentary from an elementary school focus group echoed the sentiments in all the other focus groups from this district:

P3: I know the biggest thing right now is there is a huge, huge substance abuse problem at our middle school. And they are even having special group meetings and bringing people from substance abuse treatment centers in from [major city], to talk to the parents about: "This is what's going on." [FG5]

As somewhat of a validation of Valleyview parents' expectations, a series of articles appeared in local media sources later that year regarding the County Board of Education's proposal to require middle and high school students involved in extracurricular activities to be tested for drug use at random. School district sources cited in-house student surveys that revealed increases in drug usage among middle and high school students. 


\subsubsection{Keeping and Making Good Friends}

Part of parents' expectations about the social transition into middle school reflected their anticipation that their children's relationships would be significantly disrupted. This not only included the concern that youth might fall into a bad crowd, as noted in the previous excerpts, but also the fear that they could lose old friends. Parents discussed how their children's friendships had been or could be disrupted due to class scheduling, and expected that their children would grow apart from their longer-term, established friendships. The interviewers' observations were that parents seemed to discuss this expectation with less passion and trepidation compared to the problem behavior issue, but parents' expectation was evident and consistent across groups, with no parents disagreeing that social disruption to existing relationships was a concern. Parents discussed how, first and foremost, they did not want their children to have friends who were members of "bad crowds" as a means of avoiding problem behavior; but they also desired that their children have friends who accepted them, buffered them from the social challenges of middle school, and supported and shared their values. With the exception of the parents who perceived that their children had fallen in with troubled peers, parents across focus groups appeared pleased with their children's current group of friends, but maintained apprehension for these relationships during the transition, as evidenced in these excerpts:

P2: The friends are shifting, they're moving, they're all getting in their little groups and I think she's a little apprehensive about losing some of her old friends. She hangs on pretty tight, but I think she'll be OK with it. [FG8]

P2: [Son] has met a lot of people ... It's like, "guess who I have a class with now, Mom?" But I think he's a little bit clingy toward the security of his original friends. ... I'll ask him, "Who did you eat lunch with today?" And occasionally he'll say a new name... but for the most part, it's his two best buddies that he played with, which is fine. I think he still likes the security of that. [FG4]

These two main issues related to the social nature of the middle school transition, exposure to problem behavior and loss of friends, may be interpreted as simply legitimate parental expectations about their children's peer relations and engagement in risky behavior, given known trends in adolescent adjustment. However, parents in some focus groups (FGs 5, 6, and 9) extended this discussion to include the concern that their children would be marginalized due to their social backgrounds.

\subsubsection{Vulnerabilities to Social Integration}

Parents from Perkins Elementary in Valleyview and Mountainside Elementary in Mountainside expressed an expectation that their children would be marginalized because of their values and backgrounds. In the current study, economic disparities (e.g., family educational attainment, household income) were evident between the feeder schools into each middle school, as noted in the Methods section. Although all participating schools included significant proportions of poor families with low levels of parental educational attainment, Mountainside and Perkins had notably more economically disadvantaged families than did New Mountainside and County, respectively. This disparity was particularly pronounced between Perkins and County elementary schools. New Mountainside and County served the "town" families whereas Mountainside and Perkins primarily served families in the surrounding and rural county. For parents in the focus groups from these schools, the move to middle school meant a risk of social marginalization of their youth:

M: You were talking about the two [elementary] schools being different. How are these two schools different and how is that a factor when all these kids come together?

P1: From my viewpoint, and you may disagree with me, but [Mountainside Elementary] is considered lower class.

\section{P2, P3, P4 chime in: "Right." "Lower income." "Country bumpkins."}

P1: [New Mountainside] tends to be your higher class. Your judges, your lawyers.

P3: And it is. I haul [drive the school bus] from this school, but when I take kids off to [New Mountainside] even how the kids behave on trips is totally different. And I have to say, our kids from this school tend to be a little bit more well-behaved. It's like the morals have been instilled in them more. [New Mountainside] tends to be more the wild bunch ...

P1: But I don't want him to be different [than he is]. I would hate to have my child to be, "Look. He doesn't have that." "Look at him. He's not going to fit in with us because he doesn't have that." That is hard. I was dirt-poor 
too, and I know my mama worked to try to give us the things that we had, and we didn't have the best, and I do know that we were outcasted on certain things ...

P1: But it's hard to sit there and have a group of kids not accept you. [FG9]

Explicit discussion of social class differences and parents' expectations for their effects on children's social transition was more vehemently articulated in the Mountainside compared to the Perkins (Valleyview) focus group. In Valleyview, students in County and Perkins elementaries had attended the same primary school (K-2), and thus, had some familiarity. Subsequently, parents in all Valleyview focus groups tended to speak fondly about this prior contact between students. However, as Perkins (Valleyview) parents' discussion below reveals, they too lamented the loss of the elementary school context that had affirmed their children and their families' values, and were already experiencing social exclusion from the middle school. They framed their expectation of social exclusion in relation to the power structure of the larger community that manifested itself at the middle school:

P2: I've talked to the principal [at County Middle] ... what he tells me is that ... the band parents go one direction, the sports parents go another direction, the music parents go another direction. You have three or four PTO parents, and we still have Bible in the school, a few who are willing to work with that, and he said no longer is it all intermingled and fun. It's now all segregated ...Well, I happen to know that evidently their PTO there must be a real winner ...

P1: Their PTO is $100 \%$ comprised of mothers from [County Elementary].

P2: I'm PTO president here [Perkins], and I've already been informed not to go for any job in PTO [at County Middle]. [FG5]

These aspects of the social transition also appeared to be more salient as an expectation for $5^{\text {th }}$ grade parents than as an experience to $6^{\text {th }}$ grade parents early into the transition. A few parents of $6^{\text {th }}$ graders had already witnessed a realization of dire expectations in terms of their children falling into a "bad crowd" of peers, engaging in substance use, and failing academically. However, the sentiment within each focus group tended toward apparent relief that their children had experienced a relatively easy social transition. Thus, $6^{\text {th }}$ grade parents' points of reference appeared to have changed from the hypothetical to the real. In analyzing the transcripts from the middle school groups following our identification of this perspective, we discovered that power structure and social class issues surfaced in only one group of sixth-grade parents (i.e., FG 4: County Middle in Valleyview). In this case, two mothers of children who had attended County Elementary worked through concerns about their children's' relationships with other students who had transitioned from Perkins. It is evident that the parents believed that their values were prevailing through their children's relationships at schools, either in that their family values seemed aligned despite their new friend's family background, or that their children had taken initiative to dissolve the friendships because of a clash of values (e.g., too much "F word").

\subsection{Procedural and Academic Domains of the Transition}

In contrast to the lengthy and often impassioned conversations about aspects of the social transition, parents appeared generally lighthearted about procedural aspects of the transition, contributing humorous anecdotes about their children's expectations for or experienced difficulties with their locks and changing classes. However, parents were quick to commend the schools for preparing their youth for these experiences, primarily through changing classes during $5^{\text {th }}$ grade; using academic planners; and, specifically for families in Valleyview, through providing a "summer institute" for rising sixth graders that involved two weeks of exposure to daily middle school life. Parents were enthusiastic about the experiences and we interpreted their lighthearted approach, in both school districts, as evidence of their perception that the schools were preparing and supporting their children in this regard, which may have contributed to more positive expectations for this aspect of the transition:

\section{M: [You mentioned] Organizational skills.}

P1: Her only fear was that she'd be late for class. [Summer institute] took care of that, because she found her way around the building, and she knew where everything was located, met the teachers. I think that was really good to get to know the teachers, because she felt so comfortable with the teachers right from the beginning. [FG4] 
In short, parents appeared to appreciate their children's concerns about the procedural aspects of the transition, but their own concerns appeared allayed by school-based preparation - prior to and during the transition - to minimize procedural challenges that might undermine a student's successful transition.

Parents' expectations for and perceptions of the academic domain of middle school adjustment were varied both within and across groups. Parents' concerns within groups ranged from what appeared to be no concerns (expressed by at least one parent in all groups), to an expectation or experience that preparation for the transition in $5^{\text {th }}$ grade would be or actually was more challenging than the academic work of $6^{\text {th }}$ grade, to expectations that the academic side of middle school was difficult (though notably, these were youth who struggled academically in $5^{\text {th }}$ grade, as well). Parents of students who were struggling academically volunteered either the direct experience $\left(6^{\text {th }}\right.$ grade parents) or anticipation $\left(5^{\text {th }}\right.$ grade parents) that school personnel would provide academic support, particularly if requested by parents. Thus, similar to the procedural domain, parents appeared to perceive that school personnel would provide necessary support for the academic aspect of their child's transition.

\section{Discussion of Focus Group Findings}

Parents in the current study readily discussed their expectations for social, procedural, and academic aspects of the middle school transition. The social domain of the transition featured prominently in parents' discussions and we centered our analyses on this aspect of the transition given its prevalence and the opportunity to expand on previous research by revealing parents' concerns regarding social adjustment during this period. Before discussing the results regarding the social transition more fully, we note that although the literature on rural youth contains much discussion of the dilemma of out-migration (e.g., Elder, King, \& Conger, 1996; Farmer et al., 2006; Hektner, 1995), references to educational and occupational aspirations and the role of middle school academics in those aspirations were largely absent in our focus groups. In his ethnographic study of a rural middle school in West Virginia, DeYoung (2007) observed that school administrators found it difficult to engage parents around academic issues; parents instead focused on procedural aspects of schooling such as bus schedules, which were more immediate to their experiences and were an avenue through which parents could assert some control. Less attention to academics may also reflect the reality that high school graduation, post-secondary education, and employment remain too far in the future for parents of $5^{\text {th }}$ and $6^{\text {th }}$ graders, particularly if such issues are overshadowed by parents' immediate concerns about the social aspects of the middle school transition. Perhaps in a more affluent or suburban setting, containing higher proportions of college-educated parents, parents would voice more explicit expectations about the academic transition. For instance, Akos and Galassi (2004) found parents in an affluent, highly educated community rated academics as the top middle school transition concern, although social, and procedural concerns were prevalent as well. Future research with diverse communities can help to clarify the relationship between parenting context and expectations more fully.

Within the social domain of the middle school transition, parents expressed specific concerns for their children's relationship changes and exposure to classmates who were engaged in problem behavior. Moreover, parents from particular feeder elementary schools were concerned that their children would experience social exclusion because of their social backgrounds. Parents' expectations for friendship disruption were not unfounded; research findings demonstrate the loss of old friends when rural youth move from small, local elementary schools to larger and consolidated middle schools. In a study that included the rural early adolescents and schools that participated in the current study, Hutchins (2008) found that after accounting for the availability of peers from each feeder elementary school, early adolescents tended to form peer groups with classmates from their feeder elementary school shortly after the middle school transition, which suggests a continuity of friendship early in the transition year. However, this tendency declined over time, particularly for girls, who became increasingly likely to form peer groups with peers who had attended other feeder elementary schools. In a different study of rural schools, Hardy, Bukowski, and Sippola (2002) similarly demonstrated that students, and particularly girls from the larger, rather than smaller elementary schools, lost friends from their feeder elementary in the transition to middle school and were more likely to name students from a different feeder school as friends. Gender differences around this point did not emerge in the focus groups in the present study. Finally, Hardy et al. (2002) found that although children may shift in their actual affiliations (i.e., friendships, peer groups) across the transition year, their acceptance by peers did not tend to change.

Parents from Mountainside and Perkins elementaries, specifically, expressed concern that their children would be vulnerable to social isolation and lowered status because of their feeder school affiliation. Such concerns have 
surfaced in other studies of rural youth at the point of school transition. In an ethnographic study of the middle school transition among rural youth in New England, SanAntonio (2004) noted how parents from the more remotely rural and poorer communities "...wonder if their children will be seen [emphasis in original], encouraged, and instructed in a way that acknowledges the talent, history, lifestyles, and values their children bring with them" (2004, p. 139). SanAntonio described parents' fear of exclusion of these values and, consequently, of their children, in the transition process. Rural sociologist Cynthia Duncan wrote that social class segregation is particularly salient and enduring in Appalachia. According to Duncan (2001), rigid segregation of the haves, who live in the county seat, attend the town elementary school, and dominate the parent-teacher organizations and other school events; and the have-nots, who live in the county and who are marginalized economically and socially, is rooted in the economic history of Appalachian communities (see also Thorne et al., 2007). For generations, more affluent families have sought to distinguish themselves from poor families, whom they characterize as lazy and deviant. Church affiliations and values also serve to demarcate the more advantaged from the disadvantaged as social classes do not mix in these settings and the values of more elite town churches pervade local institutions, including schools. Poor families are well aware of how they are perceived by the more affluent members of the county, and describe differential treatment within their county schools and institutions.

In spite of these concerns, results of a recent study suggest that social integration and general adjustment difficulties may be more of an apprehension than a reality following a school change. Nitta, Holley, and Wrobel (2010) studied the transition of high school students into existing high schools, under mandated cross-district consolidation. Some of the consolidations involved the integration of students from more economically and historically disadvantaged schools into schools with significantly lower proportions of students eligible for free or reduced lunch. An emergent theme was that students from smaller and more disadvantaged schools would face social integration difficulties. However, the consensus among the student and teacher participants was that students from the school that closed did not tend to experience social difficulties as the year proceeded. Teachers observed that some students did not adapt socially and left school, while others reported significant social tensions among students from the different schools. The Nitta et al. study involved only a handful of student participants from each school, and participants' recollections of the social dynamics following school consolidation. Moreover, the authors noted that the sample selection process might have excluded students who had experienced social integration difficulties.

Taken together, findings from a number of studies of rural youth suggest that students do not experience significant social adjustment difficulties as they make a school transition, but the literature lacks systematic attention to the extent to which adolescents experience social difficulties or more general adjustment difficulties following a school transition if they have attended a less affluent or otherwise disadvantaged school. Project REAL, the broader study within which the focus groups were conducted, afforded the opportunity to investigate parents' concerns that children who had attended particular feeder elementary schools would experience greater difficulty with social adjustment in the middle school transition. The larger study included survey data about the school adjustment of the majority of students in Valleyview and Mountainside Middle Schools, at the fall and spring of sixth grade. Thus, it was possible to compare the overall transition adjustment and social integration patterns of children at the beginning and end of the transition year, based on the feeder school they attended. Adjustment data were reported from children's self-reports and peer-ratings, as well as from teacher ratings, which provide a comprehensive assessment of adolescents' actual adjustment rather than parents' perceptions. Based on parents' discussions and the data available, we focused these follow-up analyses on students' perceptions of the middle school transition and their sense of school belonging; teachers' ratings of students' overall adjustment; and peer nominations that indicate classmates' social integration, including students' integration into the peer group system, peer acceptance, and peer disliking. Unfortunately, the survey data did not include questions regarding other adjustment concerns raised by parents, such as involvement in substance use and other problem behaviors (i.e., swearing) beyond aggression with peers.

\section{Methods for Follow-Up Study of Student Adjustment}

\subsection{Student Participants}

The sample of adolescent participants included $966^{\text {th }}$ graders from Mountainside Middle School and $916^{\text {th }}$ graders from Valleyview Middle School, reflecting a 58\% and 56\% parental consent rate in each school, respectively. Sixty-two percent of the Mountainside Middle School sample had attended New Mountainside elementary (the remainder had attended New Mountainside); 67\% of the total Valleyview Middle School sample 
had attended County elementary, with the remainder having attended Perkins. Proportions of male and female students were comparable in both settings ( $51 \%$ female in both middle schools).

\subsection{Measures}

Consented adolescents completed a survey instrument during the fall and spring of $6^{\text {th }}$ grade, which included information about their own and grademates' social integration, academic, and behavioral adjustment. This instrument included peer nominations to generate indicators of social standing with grademates; social cognitive mapping (SCM) procedures to identify peer group affiliations; and self-report scales that addressed aspects of school adjustment. Teachers also rated participating adolescents' social, academic, and behavioral adjustment. The measures and procedures reported have been used with samples of rural early adolescents (e.g., Farmer et al., 2003; Hamm et al., 2010; Hardy et al., 2002).

\subsubsection{Social Integration}

Following SCM procedures developed by Cairns and colleagues (e.g., Cairns, Leung, Buchanan, \& Cairns, 1995), students were asked in survey format, "Are there some kids in your classroom who hang around together a lot? Who are they?" Participants' peer group affiliations were identified following procedures explained in detail in other studies (i.e., Farmer et al., 2003; Hamm et al., 2011). Students' embeddedness, or centrality, within the social network system, was measured by the total number of times an individual was named by classmates as a member of a peer group (Farmer et al., 2003). Higher centrality scores signify greater integration into the social network system.

Peer acceptance and peer disliking were measured with a widely used procedure established by Coie, Dodge, and Coppotelli (1982). Participants were asked to list up to three peers whom they "liked most" and "liked least." Liked most scores were summed to indicate peer acceptance, and liked least scores were summed to indicate dislike; higher scores signified that a child was more liked or more disliked, respectively.

Sense of school belonging was measured by the widely used, 11-item, Psychological Sense of School Belonging-Brief (PSSM-B) scale (Hagborg, 1998). Particpants indicated their agreement with items such as, "I feel a real part of my school" on a 5 - point response scale that ranged from 1 (completely false) to 5 (completely true). Higher scores signify more favorable sense of belonging. Cronbach's alpha coefficient was .83.

\subsubsection{Perceptions of the Transition}

Participating adolescents responded to a single-item question, on a scale from 1 (difficult) to 4 (easy), "How do you think the move from elementary school to middle school was for you?"

\subsubsection{Overall Social, Behavioral, and Academic Adjustment}

Teachers completed the Interpersonal Competence Scale -Teacher version (ICS-T; Cairns, et al., 1995) for each participant in their class. The ICS-T is an 18-item questionnaire that addresses student adjustment, yielding several subscales. The following were used in the present analyses: aggression (composed of "always argues," "gets in trouble," and "always fights," Cronbach alpha =.82); popularity (composed of "popular with girls, "popular with boys," and "lots of friends," Cronbach alpha = .82), and academic (composed of "good at math" and "good at spelling," Cronbach alpha $=.71$ ). The ICS-T has convergent validity with direct observation, student records (i.e., grades, discipline reports), and peer nomination measures (Cairns \& Cairns, 1994; Cairns, et al., 1995; Rodkin, Farmer, Pearl, \& Van Acker, 2000). Items are coded so that a higher score reflects increased levels of the measured construct.

\subsection{Procedures}

All procedures used in the study were approved by the Institutional Review Board of the University of North Carolina at Chapel Hill. Project research staff visited classrooms to invite all students to participate. A letter that summarized the study and a consent form were sent home; children returned completed parental consent forms to an envelope in the classroom. Following group administration procedures used by the study's investigators for over two decades, adolescents whose parents had granted permission for participation and who assented to participate in the study were gathered in the school cafeteria to complete the survey instrument. Participants were assured of the confidentiality of their answers, and were informed that they were not required to participate and could withdraw from the study at any time. 


\section{Results of Follow-Up Analyses of Survey Data of Student Adjustment}

For all adjustment indicators, parallel analyses were conducted within the sample of students from Mountainside Middle School and within the sample of students from Valleyview Middle School, and for the beginning (fall) and end (spring) of the $6^{\text {th }}$ grade school year. A series of Analysis of Variance (ANOVA) tests were conducted to test for mean differences between feeder elementary schools for each indicator of social integration and for teacher ratings of adjustment at the fall and spring of sixth grade. Because the number of students enrolled in the feeder schools for each middle school differed considerably, the Levene statistic for the equality of group variance was tested. When the Levene statistic was significant, the Welch statistic was examined (Howell, 1997). In the few instances in which the Levene test was significant, the test of the Welch statistic yielded results similar to the test of the $F$ statistic. Differences in the distribution of students' perceptions of the middle school transition by feeder school attendance were examined at the fall and spring using a Chi-square Test of Association.

\subsection{Social Integration}

Mean and standard deviation scores are reported for each adjustment indicator in Table 3 (fall) and Table 4 (spring).

Table 3. Means and standard deviations for adjustment indicators by feeder elementary school: fall of transition year

\begin{tabular}{lllll}
\hline & \multicolumn{2}{l}{ Mountainside Middle School $(\mathrm{N}=96)$} & \multicolumn{2}{l}{ Valleyview Middle School $(\mathrm{N}=91)$} \\
& Mountainside & New Mountainside & Perkins & County \\
\cline { 2 - 5 } & $M(S D)$ & $M(S D)$ & $M(S D)$ & $M(S D)$ \\
\hline Peer acceptance & $1.08(.95)$ & $1.57(1.52)$ & $1.16(1.63)$ & $1.78(1.82)$ \\
Peer disliking & $1.31(2.22)$ & $1.07(1.85)$ & $1.26(3.10)$ & $.91(1.48)$ \\
Centrality & $6.05(6.68)$ & $6.14(6.20)$ & $5.79(4.72)^{\mathrm{a}}$ & $8.81(6.62)^{\mathrm{a}}$ \\
School belonging & $3.72(.78)$ & $3.66(.84)$ & $3.74(.66)$ & $3.56(.78)$ \\
Popularity & $4.52(.90)$ & $4.64(1.23)$ & $4.35(.78)$ & $4.45(1.30)$ \\
Aggression & $2.75(1.64)^{\mathrm{a}}$ & $2.01(1.23)^{\mathrm{a}}$ & $2.03(1.20)$ & $1.79(1.10)$ \\
Academic adjustment & $4.06(1.34)^{\mathrm{a}}$ & $4.80(1.24)^{\mathrm{a}}$ & $4.34(.92)$ & $4.62(1.38)$ \\
\hline
\end{tabular}

${ }^{\mathrm{a}}$ School means differ significantly, $p<.05$.

Note: Peer acceptance, disliking, and centrality are peer-rated; school-belonging is self-rated; and popularity, aggression, and academic adjustment are teacher-rated.

Table 4. Means and standard deviations for adjustment indicators by feeder elementary school: spring of transition year

\begin{tabular}{lllll}
\hline & \multicolumn{2}{l}{$\begin{array}{l}\text { Mountainside Middle School }(\mathrm{N}=96) \\
\text { Malleyview Middle School }(\mathrm{N}=91)\end{array}$} \\
\cline { 2 - 5 } & $M(S D)$ & $M(S D)$ & $M(S D)$ & $M(S D)$ \\
\hline Peer acceptance & $1.64(1.48)$ & $1.72(1.71)$ & $1.16(1.63)$ & $1.78(1.82)$ \\
Peer disliking & $1.39(2.60)$ & $1.18(2.06)$ & $1.26(3.10)$ & $.91(1.48)$ \\
Centrality & $9.08(8.29)$ & $8.58(8.71)$ & $8.30(7.02)$ & $10.55(9.06)$ \\
School belonging & $3.62(.72)$ & $3.70(.79)$ & $3.50(.71)$ & $3.54(.75)$ \\
Popularity & $4.53(1.07)$ & $4.55(1.19)$ & $4.52(1.13)$ & $4.24(1.25)$ \\
Aggression & $3.26(1.74)^{\mathrm{a}}$ & $2.40(1.51)^{\mathrm{a}}$ & $2.54(1.48)$ & $1.88(1.37)$ \\
Academic adjustment & $3.93(1.32)^{\mathrm{a}}$ & $4.86(1.14)^{\mathrm{a}}$ & $4.28(.97)$ & $4.86(1.48)$ \\
\hline
\end{tabular}

${ }^{\mathrm{a}}$ School means differ significantly, $p<.01$.

Note: Peer acceptance, disliking, and centrality are peer-rated; school-belonging is self-rated; and popularity, aggression, and academic adjustment are teacher-rated. 


\subsubsection{Mountainside}

Adolescents from New Mountainside and Mountainside elementary schools experienced similar levels of centrality in the social network system; that is, they received comparable numbers of nominations into peer groups at the fall of sixth grade, $F(1,93)=.01, p=.95$. Similarly, no significant differences in social network centrality were found for the spring of sixth grade, $F(1,93)=.08, p=.79$. These findings indicated that participants from each feeder school were similarly integrated into the peer group system of sixth grade.

For peer acceptance, no significant differences were found between feeder schools at the fall, $F(1,93)=2.84, p$ $=.10$, or spring of sixth grade, $F(1,94)=.05, p=.82$. Similarly, for peer disliking, adolescents from Mountainside and New Mountainside did not differ at either the fall, $F(1,93)=.34, p=.56$ or spring of sixth grade, $F(1,94)=.18, p=.67$.

Finally, differences in participants' sense of school belonging were assessed by feeder school attendance. At the beginning of sixth grade, adolescents from both feeder elementary schools reported comparable - and generally favorable - levels of school belonging, $F(1,93)=.13, p=.72$. This pattern was evident again at the end of sixth grade, $F(1,91)=.21, p=.65$.

\subsubsection{Valleyview}

Differences in centrality, or the number of nominations received for belonging to a peer group were significant at the beginning of the school year, $F(1,89)=3.90, p=.05$. Participants who had attended Perkins received fewer nominations than did students who had attended County. However, by the end of sixth grade, adolescents did not differ in social network centrality based on feeder school attendance, $F(1,89)=1.17, p=.28$. Thus, adolescents from Perkins did experience less social integration into the peer group system early in the transition, but were similarly integrated by the end of the school year.

No significant differences were evident between feeder schools for peer acceptance at either the fall, $F(1,90)=$ $1.30, p=.25$, or spring time points, $F(1,90)=1.01, p=.32$. Likewise, participants from Perkins and County elementary experienced similar levels of peer disliking at the fall, $F(1,90)=1.19, p=.28$, and spring, $F(1,90)$ $=.004, p=.95$, of sixth grade.

Finally, no significant differences were found between Perkins and County for sense of school belonging at either the beginning of sixth-grade, $F(1,85)=.91, p=.34$, or the end of sixth-grade, $F(1,85)=.06, p=.82$. Adolescents from both feeder schools started and ended sixth grade with a similarly positive sense of connection to Valleyview Middle School.

\subsection{Teacher-Rated Social, Behavioral, and Academic Adjustment}

Means and standard deviations for teachers' ratings are reported in Tables 3 (fall) and 4 (spring).

\subsubsection{Mountainside}

Teacher ratings of adolescents' popularity with peers did not differ significantly by feeder school attendance at either the fall, $F(1,88)=.24, p=.62$, or the spring, $F(1,88)=.007, p=.93$, of sixth grade. However, teacher ratings differed according to feeder school attendance for both aggression and academic adjustment. Adolescents from Mountainside were rated as more aggressive than adolescents from New Mountainside at the fall, $F(1,88)$ $=5.89, p=.017$ and spring, $F(1,88)=6.34, p=.013$. Similarly, adolescents from Mountainside were rated as a less academically successful at the fall, $F(1,88)=7.18, p=.009$, and the spring, $F(1,88)=10.20, p=.002$.

6.2.2 Valleyview. Teacher ratings did not differ significantly for adolescents who had attended Perkins versus County elementary schools, for any of the adjustment domains. Specifically, adolescents from each feeder were rated similarly for popularity at the fall time point, $F(1,76)=.105, p=.75$, and the spring time point, $F(1,87)$ $=.93, p=.34$; for aggression at the fall time point, $F(1,76)=.70, p=.40$, and the spring time point, $F(1,87)=$ $3.75, p=.06$; and for academic adjustment at the fall time point, $F(1,76)=.77, p=.38$, and the spring time point, $F(1,87)=3.07, p=.08$. Means and standard deviations for each adjustment indicator are reported in Tables 3 and 4 for fall and spring, respectively.

\subsection{Perception of the Transition}

\subsubsection{Mountainside}

Results of the chi-square analysis indicated that at the beginning of sixth grade, adolescents from Mountainside elementary school maintained significantly less favorable views of how the transition was proceeding than did adolescents who had attended New Mountainside elementary school, $\chi^{2}(3)=12.50, p<.006$. As represented in 
Table 5, only about half of the participants from Mountainside elementary perceived the transition as somewhat easy or easy, and approximately one-third perceived it as somewhat difficult. In contrast, the vast majority of participants $(86.5 \%)$ who had attended New Mountainside elementary reported that their experience of the middle school transition was somewhat easy or easy.

Differences in perceptions of the transition remained at the end of sixth-grade, $\chi^{2}(3)=10.24, p<.017$. As reported in Table 5, in the spring, $60.0 \%$ of the Mountainside participants viewed the transition as somewhat easy or easy, whereas $87.5 \%$ of the New Mountainside participants perceived the transition favorably. Although the percentage for Mountainside was somewhat higher than was the case in the fall, it is noteworthy that $20 \%$ of participants from Mountainside ended sixth grade perceiving that the transition year had been very difficult.

\subsubsection{Valleyview}

Results of the chi-square analysis indicated that at the beginning of sixth grade, adolescents from Perkins and County elementary schools did not differ in their perceptions of how the middle school transition was proceeding, $\chi^{2}(3)=1.79, p=.62$; this similar view of the middle school transition was present at the end of sixth-grade, $\chi^{2}(3)$ $=4.38, p=.22$. As shown in Table 5, over $75 \%$ of participants from either feeder elementary reported that the transition was somewhat easy or easy at both the beginning and end of sixth grade.

Table 5. Students' perceptions of the difficulty of the middle school transition, by feeder elementary and time of year

\begin{tabular}{lllll}
\hline & Mountainside & \multicolumn{2}{l}{ New Mountainside } & Perkins \\
& $\%$ & $\%$ & $\%$ & $\begin{array}{l}\text { County } \\
\%\end{array}$ \\
\hline Fall & & & & \\
Very Difficult & 12.5 & 5.1 & 4.5 & 6.5 \\
Somewhat Difficult & 34.4 & 8.5 & 18.2 & 8.1 \\
Somewhat Easy & 21.9 & 37.3 & 22.7 & 24.2 \\
Very Easy & 31.2 & 49.2 & 54.5 & 61.3 \\
Spring & & & & \\
Very Difficult & 20.0 & 3.6 & 4.3 & 6.3 \\
Somewhat Difficult & 20.0 & 8.9 & 13.0 & 14.3 \\
Somewhat Easy & 22.9 & 39.3 & 17.4 & 38.1 \\
Very Easy & 37.1 & 48.2 & 65.2 & 41.3 \\
\hline
\end{tabular}

\section{Interpretation of the Follow-Up Analyses in Relation to Parents' Concerns}

The purpose of the follow-up analyses was to examine, systematically, concerns raised by parents in the focus groups regarding differential patterns of adolescents' adjustment in middle school based on feeder school attendance. Multiple indicators of social integration, as rated by peers, teachers, and self were considered, as were teacher reports of behavioral and academic adjustment, and adolescents' own perceptions of the transition. The results of these analyses indicated that contrary to Mountainside parents' concerns, adolescents from Mountainside elementary school did not experience greater social integration difficulties than their peers from New Mountainside, as indicated by comparable levels of centrality, peer accepting and disliking, popularity, and school belonging. However, a significantly greater proportion of adolescents from Mountainside perceived the transition more negatively than their peers from New Mountainside. Moreover, teacher ratings indicated that adolescents from Mountainside were having greater difficulty with behavioral and academic aspects of the transition, as compared to adolescents from New Mountainside. In Valleyview, differences in social integration and adjustment between adolescents from Perkins and County were not pronounced. The only difference that emerged was that adolescents from Perkins, as compared to County, experienced significantly less integration into the sixth-grade social network system, but only at the beginning of the transition year. 
Thus, parents' fears regarding social marginalization were not realized for adolescents from Mountainside, and were only somewhat of an issue for adolescents from Perkins early in the transition year. Although adolescents do expand their social networks beyond the peers from their feeder school (Hardy et al., 2002; Hutchins, 2008), adolescents from feeder schools that were less affluent and prominent in the community did not seem to experience greater difficulty making these adjustments. The follow-up analyses provide a thorough examination of this issue for the majority of students in each middle school, at the beginning and end of the transition year, and with respect to numerous indicators of social integration. The findings are aligned with Nitta, et al.'s (2010) conclusion that, despite fears for social difficulties for adolescents who come from more disadvantaged feeder schools, students find their social niche after a school transition.

The primary difference that emerged was that significantly more adolescents from Mountainside elementary perceived the middle school transition to be more difficult than did their classmates who transitioned to middle school from New Mountainside elementary school, a finding that was corroborated by teachers' reports. This difference in adjustment persisted across the school year. Thus, parents may have discerned some sort of transition difficulty for children from Mountainside that they attributed to the social domain, but in the absence of evident social difficulties, it seems unlikely that social integration was a dominant factor in adolescents' overall adjustment difficulties. Teacher ratings indicated that adolescents from Mountainside experienced greater academic difficulties and were more aggressive. Thus, it is noteworthy that parents' concerns about a more difficult transition were realized for youth, but not seemingly based in social integration, as parents feared.

In summary, the findings from the follow-up analyses, based in the patterns of social integration of two middle schools in different rural Appalachian communities provided direct evidence that following the middle school transition, students from more economically disadvantaged feeder schools tended to find early and sustained social integration in their new schools. As noted by Nitta, et al. (2010), such findings speak to adolescents' flexibility in adjusting to new social opportunities and suggest that the social integration of youth from diverse feeder schools may not merit the level of concern that it evokes from adults. However, adolescents from different feeder schools may experience persistent difficulty in adjusting to middle school, which suggests continued attention to the implications of moving from less economically advantaged and/or smaller feeder elementary schools.

\section{Strengths and Limitations, and Implications for Schools}

A strength of this investigation was the use of a qualitative approach that allowed parents to discuss their views about the transition with other parents, using their own language and shared experiences in their communities and children's schools. We kept our questions about the middle school transition general, intending to launch a conversation among parents without imposing particular structure or themes on the discussion. By allowing parents to direct the discussions around expectations they deemed significant, we were able to gain greater insight into how they conceptualized particular broad dimensions of the middle school transition, and what it was about their own community contexts that made these themes salient. The analysis of the quantitative data regarding the actual social integration and general adjustment patterns of adolescents is a strength; these findings did not validate parents' concerns but rather highlighted an area of need for school programming efforts. Moreover, the inclusion of the quantitative data provided systematic study of a recurring issue that has received little direct empirical attention.

This design of the study is not without limitations. The study included families from two communities in two Appalachian states. Although Appalachia as a region is considered to be a unique cultural context of development (Wilson \& Peterson, 2000), it is a diverse region in itself, with meaningful between- and within-community diversity (Thorne et al., 2007). Participants in this study cannot be considered fully representative of rural Appalachian families. Furthermore, it is difficult to ascertain the extent to which the participants represent a unique collection of individuals within the communities and schools from which they were recruited. We worked carefully with school personnel to invite a diverse array of families to participate, specifically to include families that varied in terms of their relationship with the school and the successful school adjustment of their youth. As is evidenced by our presentation of quotations, we had families whose youth had navigated the transition without problems and families whose youth had or were currently struggling to adjust socially, behaviorally, and academically. Further, parents varied in how positively they viewed the school and its efforts and in terms of their school involvement. However, those individuals who arrived to participate in these groups shared some important commonalities: an interest in and concern over the middle school transition for their children, and a desire to talk with other parents about their perspectives and experiences. The ideas that 
surfaced consistently across groups may reflect perspectives of parents who are concerned about this transition, or who have already given thought to the middle school transition.

Finally, this study focused on a one-time account of parents' beliefs either prior to or at the end of the middle school transition year. More informative, but beyond the scope of the study, would have been to interview the same parents pre- and post-transition, to track the evolution of their concerns and experiences. The findings from the present study, as well as the other qualitative studies relevant to this topic, suggest that there is much to be learned about parents' expectations for this transition. The limitations inherent in the design of the present study should be addressed in future work, perhaps by administering a survey informed by the qualitative literature to all parents prior to, at the beginning, and at the end of the middle school transition year.

Taken together, the findings suggest a number of implications for schools interested in promoting student success in the middle school transition through parents. Middle school personnel typically provide information sessions for parents about the middle school transition. Informational materials commonly used in these events (i.e., prepared by the U.S. Department of Education Office of Communication and Outreach and by the National Association of School Counselors) speak to diverse but general issues about the transition. These issues may not reflect the specific concerns that parents have about the transition and tend to highlight procedural more than social challenges of the transition. The present findings portray the specificity of concerns that can be present between schools but do not likely generalize to all rural school contexts.

A broader point to take from these findings is that it would be advisable for school personnel to determine the nature of concerns maintained by parents in the communities served by the middle school. Furthermore, given the recurring attention across diverse studies to the social adjustment of adolescents following building transitions, school personnel should anticipate the need to discern the specific nature of parents' concerns and to provide information about the social aspect of the transition. A suggestion for school personnel would be to collect the same types of data for their students that were used in the follow-up analyses, and compare students' adjustment from different feeder schools to confirm that there are not systematic differences between feeder schools in terms of social integration or other aspects of adjustment. If differences are present, school personnel could follow up with proactive measures such as social contact opportunities prior to the transition. An absence of differences could be presented to parents in a manner that helped to assuage parent concerns. However, the findings from the present study do highlight the potential for feeder school differences in student adjustment. Middle school personnel in communities that have significant discrepancies among their elementary schools may find it useful to attend to feeder school differences in student success in the middle school transition. To the extent that differences arise - whether social, academic, or behavioral - programming can take place prior to and during the transition that may help students from particular feeder schools experience a more favorable transition.

Issues of school transition will continue to exist for rural youth, whether due to normative schooling transitions, such as the move to middle school, or due to school consolidation proceedings. When schooling transitions are understood not simply in terms of students' readiness and school factors, but more broadly as transitions that include parent expectations and preparation of youth that reflect the cultural context of families and schools (Doucet \& Tudge, 2007), student adjustment in school transitions may be enhanced.

\section{Acknowledgement}

The research reported here was funded by the Institute of Education Sciences, U.S. Department of Education, through Grant R305A04056 to the University of North Carolina at Chapel Hill. The opinions expressed are those of the authors and do not represent views of the Institute or the U.S. Department of Education. The authors thank Jana Thompson for her assistance with the study.

\section{References}

Akos, P., \& Galassi, J. P. (2004). Middle and high school transitions as viewed by students, parents, and teachers. Professional School Counseling, 7, 212-221.

Ali, S. R., \& Saunders, J. L. (2008). The career aspirations of rural Appalachian high school students. Journal of Career Assessment, 17, 172-188. http://dx.doi.org/10.1177/1069072708328897

Anderman, E. M., \& Mueller, C. (2009). Middle school transitions and adolescent development. In J. Meece, \& J. Eccles (Eds.), Handbook of Research on Schools, Schooling, and Human Development. New York: Routledge. 
Bard, J., Gardener, C., \& Wieland, R. (2006, Winter). Rural school consolidation: History, research summary, conclusions, and recommendations. Rural Educator, 27(2), 40-48.

Beaulieu, L. J., Israel, G. D., \& Wimberley, R. C. (2003). Promoting educational achievement: A partnership of families, schools and communities. In D. L. Brown, \& L. E. Swanson (Eds.), Challenges for Rural America in the Twenty-First Century (pp. 273-289). University Park, PA: The Pennsylvania State University Press.

Buchanan, C. M., \& Hughes, J. L. (2009). Construction of social reality in early adolescence: Can expecting storm and stress increase storm and stress? Journal of Research on Adolescence, 19(2), 261-285. http://dx.doi.org/10.1111/j.1532-7795.2009.00596.x

Cairns, R. B., \& Cairns, B. D. (1994). Lifelines and risks: Pathways of youth in our time. New York: Cambridge University Press.

Cairns, R. B., Leung, M., Buchanan, L., \& Cairns, B. D. (1995). Friendships and social networks in childhood and adolescence: Fluidity, reliability, and interrelations. Child Development, 66(5), 1330-1345. http://dx.doi.org/10.1111/1467-8624.ep9510075266

Cairns, R. B., Xie, H., \& Leung, M. C. (1998). The popularity of friendship and the neglect of social networks: Toward a new balance. New Directions for Child Development, 81, 25-53. http://dx.doi.org/10.1002/cd.23219988104

Coie, J. D., Dodge, K. A., \& Coppotelli, H. (1982). Dimensions and types of social status: A cross-age perspective. Developmental Psychology, 18, 557-570. http://dx.doi.org/10.1037/0012-1649.18.4.557

DeYoung, A. J. (2007). Constructing and staffing the cultural bridge: The school as change agent in rural Appalachia. In P. J. Obermiller, \& M. E. Maloney (Eds.), Appalachia: Social context past and present (pp. 137-163). Dubuque, IA: Kendall/Hunt.

DeYoung, A. J., Howley, C., \& Theobald, P. (1995). The cultural contradictions of middle schooling for rural community survival. Journal of Research in Rural Education, 11, 24-35. Retrieved from http://jrre.psu.edu/articles/v11,n3,p187-197,DeYoung.pdf

Doucet, F., \& Tudge, J. (2007). Co-constructing the transition to school: Reframing the novice versus expert roles of children, parents, and teachers from a cultural perspective. In R. Pianta, M. J. Cox, \& K. Snow (Eds.), School readiness and the transition to kindergarten in the era of accountability (pp. 307-328). New York: Paul Brookes.

Duncan, C. M. (2001). Social capital in America's poor rural communities. In S. Saegert, J. P. Thompson, \& M. Warren (Eds.), Social capital and poor communities (pp. 60-88). New York: Russell Sage.

Duncombe, W., \& Yinger, J. (2007). Does school district consolidation cut costs? Education Finance and Policy, 2, 341-375. http://dx.doi.org/10.1162/edfp.2007.2.4.341

Eccles, J., Midgley, C., Wigfield, A., Buchanan, C., Reuman, D., Glanagan, C., \& MacIver, D. (1993). Development during adolescence: The impact of stage-environment fit on young adolescents' experiences in schools and in families. American Psychologist, 48, 90-101. http://dx.doi.org/10.1037/0003-066X.48.2.90

Elder, G. H., King, V., \& Conger, R. D. (1996). Attachment to place and migration prospects: A developmental perspective. Journal of Research on Adolescence, 6(4), 397-425.

Farmer, T. W., Dadisman, K., Latendresse, S. J., Thompson, J., Irvin, M. J., \& Zhang, L. (2006). Educating out and giving back: Adults' conceptions of successful outcomes of African American high school students from impoverished rural communities. Journal of Research in Rural Education, 21(10). Retrieved from http://jrre.psu.edu/articles/21-10.pdf

Farmer, T. W., Estell, D. B., Bishop, J. L., O’Neal, K. K., \& Cairns, B. D. (2003). Rejected bullies or popular leaders? The social relations of aggressive subtypes or rural African American early adolescents. Developmental Psychology, 39(6), 992-1004. http://dx.doi.org/10.1037/0012-1649.39.6.992

Farmer, T. W., Price, L., O’Neal, K. K., Leung, M. C., Goforth, J. B., Cairns, B. D., \& Reese, L. E. (2004). Exploring risk in African-American youth. American Journal of Community Psychology, 33, 51-59. http://dx.doi.org/10.1023/B:AJCP.0000014318.16652.30 
Griffin, D. C., Hutchins, B. C., \& Meece, J. L. (2011). Where do rural high school students go to find information for their futures? Journal of Counseling and Development, 89, 172-181. http://dx.doi.org/10.1002/j.1556-6678.2011.tb00075.x

Hagborg, W. J. (1998). School membership among students with learning disabilities and nondisabled students in a semirural high school. Psychology in the Schools, 35, 183-188. http://dx.doi.org/10.1002/(SICI)1520-6807(199804)35:2<183::AID-PITS10>3.0.CO;2-8

Hamm, J. V., Farmer, T. W., Robertson, D., Dadisman, K. A., Murray, A., Meece, J. L., \& Song, S. Y. (2010). Effects of a developmentally based intervention with teachers on Native American and White early adolescents' schooling adjustment in rural settings. The Journal of Experimental Education, 78, 343-377. http://dx.doi.org/10.1080/00220970903548038

Hardy, C., Bukowski, W. M., \& Sippola, L. K. (2002). Stability and change in peer relationships during the transition to middle-level school. Journal of Early Adolescence, 22, 117-142. http://dx.doi.org/10.1177/0272431602022002001

Hektner, J. M. (1995). When moving up implies moving out: Rural adolescent conflict in the transition to adulthood. Journal of Research in Rural Education, 11, 3-14. Retrieved from http://www.jrre.psu.edu/articles/v11,n1,p3-14,Hektner.pdf

Hughes, D., \& Dumont, K. (1993). Using focus groups to facilitate culturally-anchored research. American Journal of Community Psychology, 21(4), 775-806. http://dx.doi.org/10.1007/BF00942247

Hutchins, B. C. (2008). Finding new friends or falling back on familiar faces: The peer affiliations of aggressive students following the transition to middle school. Unpublished Master's Thesis, University of North Carolina at Chapel Hill.

Jacobs, J., Chhin, C. S., \& Shaver, K. (2005). Longitudinal links between perceptions of adolescence and the social beliefs of adolescence: Are parents' stereotypes related to beliefs held about and by their children? Journal of Youth \& Adolescence, 34, 61-72. http://dx.doi.org/10.1007/s10964-005-3206-x

Karriker-Jaffe, K. J., Foshee, V. A., Ennett, S. T., \& Suchindran, C. (2008). The development of aggression during adolescence: Sex differences in trajectories of social and physical aggression among youth in rural areas. Journal of Abnormal Child Psychology, 36, 1227-1236. http://dx.doi.org/10.1007/s10802-008-9245-5

Krueger, R. A. (1994). Focus groups: A practical guide for applied research. Thousand Oaks, CA: Sage Publications.

Lewis, J. (2006). The long and winding road: Consolidation - The separation of school and community. Retrieved March 14, 2006, from http://www.challengewv.org/ news /long_winding_road.pdf

Nitta, K., Holley, M., \& Wrobel, S. (2010). A phenomenological study of rural school consolidation. Journal of Research in Rural Education, 25(2), 1-19. Retrieved from http://jrre.psu.edu/articles/25-2.pdf

Owens, J. S., Richerson, L., Murphy, C. E., Jagelewski, A., \& Rossi, L. (2007). Parent perspective: Informing the cultural sensitivity of parenting programs in rural communities. Child and Youth Care Forum, 36, 179-194. http://dx.doi.org/10.1007/s10566-007-9041-3

Perry, C. M., \& McIntyre, W. G. (2001). School connection as school reform in rural schools. The School Community Journal, 11, 57-64. $\quad$ Retrieved from http://www.adi.org/journal/fw01\%5CPerry\%20\&\%20McIntire.pdf

Peshkin, A. (1978). Growing up American. Chicago: University of Chicago Press.

Peshkin, A. (1982). The imperfect union: School consolidation and community conflict. Chicago: The University of Chicago Press.

SanAntonio, D. M. (2004). Adolescent lives in transition: How social class influences the adjustment to middle school. Albany, NY: SUNY Press.

Semke, C. A., \& Sheridan, S. A. (2012). Family-school connections in rural education settings: A systematic review of the literature. School Community Journal, 22, 21-47. Retrieved from http://www.adi.org/journal/2012ss/SemkeSheridanSpring2012.pdf

Spence, B. (2000). Long school bus rides: Stealing the joy of childhood. Charlestown, WV: Challenge West Virginia. Retrieved January 9, 2012, from http://www.wvcovenanthouse.org/challengewv 
Stanley, L. R., Comello, M. L. G., Edwards, R. W., \& Marquart, B. (2008). School adjustment in rural and urban communities. Do students from "Timbuktu" differ from their "City Slicker" peers? Journal of Youth \& Adolescence, 37, 225-238. http://dx.doi.org/10.1007/s10964-007-9180-8

Thorne, D., Tickamyer, A., \& Thorne, M. (2007). Poverty and income in Appalachia. In P. J. Obermiller, \& M. E. Maloney (Eds.), Appalachia: Social context past and present (pp. 205-216). Dubuque, IA: Kendall/Hunt.

Tompkins, R. (2006). Small schools, small districts: Good for rural kids, economies, and democracy. Retrieved April 13, 2006 from http://www.demos.org/pubs/KitchenTable014.pdf

Vernon-Feagans, L., Gallagher, K., \& Kainz, K. (2010). The transition to school in rural America: A focus on literacy. In J. Meece, \& J. Eccles (Eds.), Schools, Schooling, and Human Development. New York, NY: Routledge, Taylor, and Associates.

Wallace, L. A., \& Diekroger, D. K. (2000). The ABC's in Appalachia: A descriptive view of perceptions of higher education in Appalachian culture. Paper presented at the Women of Appalachia Conference, Ohio University, Zanesville, $\mathrm{OH}$.

Wilson, S. M., \& Peterson, G. W. (2000). Growing up in Appalachia: Ecological influences on adolescent development. In R. Montemayor, G. R. Adams, \& T. P. Gullotta (Eds.), Adolescent diversity in ethnic, economic, and cultural contexts (pp. 75-109). Thousand Oaks: Sage.

Wilson, S. M., Peterson, G. W., \& Wilson, P. (1993). The process of educational and occupational attainment of adolescent females from low-income, rural families. Journal of Marriage and the Family, 55, 158-175. http://dx.doi.org/10.2307/352966

Witherspooon, D. M., \& Ennett, S. (2011). Stability and change in rural youths' educational outcomes through the middle and high school years. Journal of Youth \& Adolescence, 40, 1077-1090. http://dx.doi.org/10.1007/s10964-010-9614-6

\section{Copyrights}

Copyright for this article is retained by the author(s), with first publication rights granted to the journal.

This is an open-access article distributed under the terms and conditions of the Creative Commons Attribution license (http://creativecommons.org/licenses/by/3.0/). 